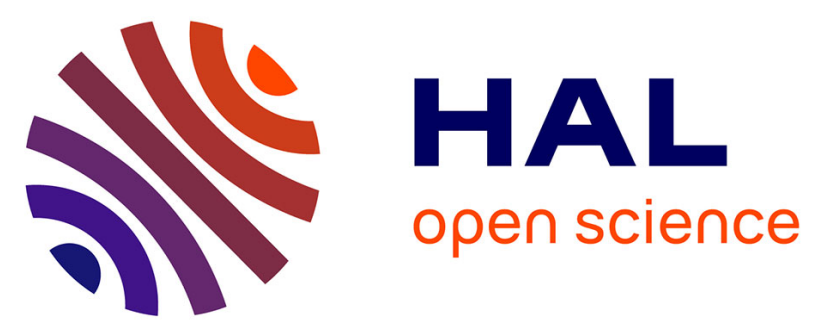

\title{
A Pareto Optimal Design Approach for Simultaneous Control of Thinning and Springback in Stamping Processes
}

Rosa Di Lorenzo, Giuseppe Ingarao, Fabrizio Micari, Francisco Chinesta

\section{- To cite this version:}

Rosa Di Lorenzo, Giuseppe Ingarao, Fabrizio Micari, Francisco Chinesta. A Pareto Optimal Design Approach for Simultaneous Control of Thinning and Springback in Stamping Processes. 12th International ESAFORM Conference on Material Forming, 2009, Twente, Netherlands. hal-01007789

\section{HAL Id: hal-01007789 \\ https://hal.science/hal-01007789}

Submitted on 11 Nov 2017

HAL is a multi-disciplinary open access archive for the deposit and dissemination of scientific research documents, whether they are published or not. The documents may come from teaching and research institutions in France or abroad, or from public or private research centers.
L'archive ouverte pluridisciplinaire HAL, est destinée au dépôt et à la diffusion de documents scientifiques de niveau recherche, publiés ou non, émanant des établissements d'enseignement et de recherche français ou étrangers, des laboratoires publics ou privés. 


\title{
A PARETO OPTIMAL DESIGN APPROACH FOR SIMULTANEOUS CONTROL OF THINNING AND SPRINGBACK IN STAMPING PROCESSES
}

\author{
Rosa Di Lorenzo $^{1 *}$, Giuseppe Ingarao ${ }^{1}$, Fabrizio Micari ${ }^{1}$, Francisco Chinesta $^{2}$ \\ ${ }^{1}$ Università di Palermo, Dip. di Tecnologia Meccanica Produzione e Ingegneria Gestionale \\ Viale delle Scienze-90128 Palermo (Italy) \\ ${ }^{2}$ LMSP UMR CNRS-ENSAM, 151 Boulevard de l'Hopital, 75013 Paris, France
}

\begin{abstract}
One of the most relevant research issues in automotive field is focused on the reduction of stamped parts weight also increasing their strength. In this way, a strong research effort is developed on high strength steels which are widely utilized and they require a proper springback control. Springback reduction in sheet metal forming is a typical goal to be pursued which is conflicting with thinning reduction for instance. Thus, such problems can be considered as multi-objective ones characterized by conflicting objectives. What is more, nowadays, a great interest would be focused on the availability of a cluster of possible optimal solutions instead of a single one, particularly in an industrial environment. In this paper, integration between numerical simulations, response surface methodology and Pareto optimal solutions search techniques was applied in order to design a DP 600 U-channel shape stamping operation. In particular the friction conditions and blank holder force were optimized as design variables in order to accomplish two different objectives: reduce excessive thinning and avoid excessive geometrical distortions due to springback occurrence.
\end{abstract}

KEYWORDS: sheet metal stamping; thinning; springback; response surface method; multi-objective optimization

\section{INTRODUCTION}

One of the most relevant research issues in automotive field is focused on the reduction of stamped parts weight also increasing their strength. Such issue led to the success of materials such as high strength steels (TRIP, DP etc) which are characterized by a strong springback occurrence after forming operations [1-3].

One of the main topics, for springback control in sheet metal forming concerns, nowadays, the numerical simulations calibration. In particular, the main issues regard: calibration of numerical parameters [4,5]; constitutive model influence on springback [6] process parameters effects [7].

In sheet metal forming most of the problems are multi objective problems, generally characterized by conflicting objectives. A typical example of optimization problem in sheet metal forming characterized by conflicting goals is the definition of proper parameters aimed to prevent both fracture and springback shape defects. What is more, nowadays, a great interest would be focused on the availability of a cluster of possible optimal solutions instead of a single one. Thus, the design parameters calibration, accomplishing all the objectives, is difficult and sometimes unsuccessful. In order to overcome this drawback a multi-objectives optimization procedure based on Pareto optimal solution search techniques seems a very attractive approach to deal with sheet metal forming processes design $[8,9]$.

In this paper, integration between numerical simulations, response surface methodology and Pareto optimal solutions search techniques was applied in order to design a DP 600 U-channel shape stamping operation.

In particular the friction conditions and blank holder force were optimized as design variables in order to accomplish two different objectives: reduce excessive thinning and avoid excessive geometrical distortions due to springback occurrence $[10,11]$.

The steps of the optimization procedure include the application of Central Composite Design (CCD) for the identification of the necessary data over the domain of variation of the design variables; then numerical simulations (explicit-implicit formulation) of the samples identified by CCD are run and data on output variables are collected. The following steps concern the development of a response surface model to interpret the final objectives as functions of the design variables and their validation; finally, Pareto optimal solutions analysis to reach the most performing design variables is performed.

\footnotetext{
* Corresponding author: Dipartimento di Tecnologia Meccanica, Produzione e Ingegneria Gestionale, Università di Palermo viale delle Scienze 90128, Palermo, ITALY

phone: +39 091 23861856; fax: +390916657039; E-mail: rosanna@dtpm.unipa.it
} 
The final aim is to develop a predictive tool able to identify a sort of process window for the analyzed process also minimizing the computational effort, in particular with respect to mono-objective optimization techniques or traditional trial and error methods.

Many possible technological scenarios were investigated by the implemented procedure and a set of reliable solutions, able to satisfy different design requirements, was obtained.

\section{THE ANALYZED PROCESS}

The considered forming process is a typical stamping one aimed to obtain an S-shaped U-channel (See Figure1 for a sketch of the investigated process). A drawn height of $15 \mathrm{~mm}$ was taken into account. The utilized material was a $1 \mathrm{~mm}$ thick DP-600 high strength steel for which the following flow rule was obtained through a campaign of tensile tests developed on $0^{\circ}$ direction specimens: $\sigma=1008 \varepsilon^{0.169}[\mathrm{MPa}]$.

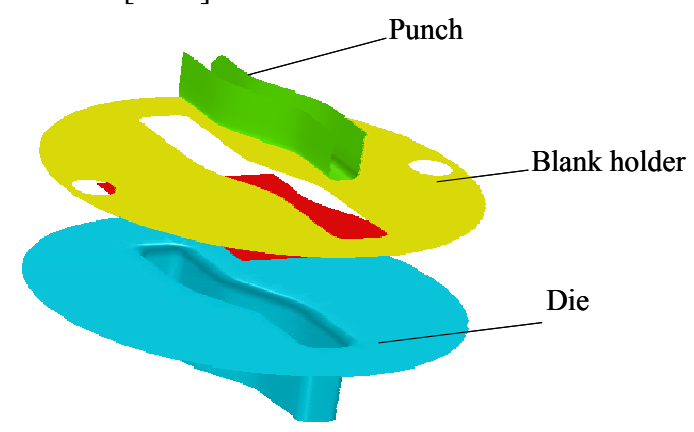

Figure 1: Sketch of the analysed process

The following Lankford's anisotropy parameters were also determined: $\mathrm{r}_{0^{\circ}}=0.73 ; \mathrm{r}_{45^{\circ}}=0.9 ; \mathrm{r}_{90^{\circ}}=0,93$.

The process was numerically simulated using the explicit code LS-DYNA, and a subsequent springback analysis was carried out with the implicit solver of LS-DYNA.

According to previous experiences on these numerical models [5], a full integrated quadrilateral shell element with 9 integration points along thickness was utilized; in particular, the starting element size is $3 \mathrm{~mm}$ and a three levels geometric remeshing strategy was applied all over the numerical simulations. The total number of elements at the end of the explicit simulations was higher than 4000; a Coulomb model was considered for frictional actions. In order to take into account material anisotropy the Barlat-Lian constitutive model [12] with an isotropic work hardening was utilized. In order to evaluate the entity of springback, at the end of the implicit simulation, a comparison with a reference target shape was performed utilizing a CAD tool. In particular, the total deviation error between such target shape and the obtained one was calculated (i.e. the maximum normal distance between the two overlapped surfaces).

\section{THE OPTIMIZATION PROBLEM}

The optimization problem taken into account aims to minimize thinning in the final part (in order to prevent fracture) and also to minimize springback occurrence.

Thus, two objective functions were defined in the modeling phase of the investigated problem: $t \%$ measuring the maximum thinning on the final part and $d[\mathrm{~mm}]$ which is the maximum deviation of the final part shape from the fixed target shape. The problem modeling also consists of the design variables definition: in the investigated process two design variables were chosen, namely friction coefficient $(\mu)$ and blank holder force value (BHF $[\mathrm{kN}])$.

Actually, the chosen design variables are related to the analyzed objective functions since such variables strongly influence the restraining forces over the sheet during the process thus influencing both thinning and springback entity.

Once the optimization problem was modeled, the workflow procedure applied in the present paper was developed according to the following steps:

Step1. Planning of the numerical simulations to be run through a proper Design of Experiments (DOE) definition;

Step2. Numerical simulations development according to the designed DOE;

Step3. Collection of numerical data obtained on thinning ( $t \%)$ and springback amount $(d)$ for each of the conditions identified by the DOE;

Step4. Meta-modeling step: analytical formulation of a response surface describing each objective function as a function of the design variables;

Step5. Evaluation of the accuracy of the obtained response surfaces in terms of error of the predictions provided by the response surfaces with respect to the actual numerical values (such evaluation was developed on properly selected points of the design domain);

Step6. Application of the $\varepsilon$-constraint procedure in order to perform a multi objective optimization i.e. to determine optimal Pareto solutions.

As step 1 is regarded, the Central Composite Design (CCD) architecture was selected to design the set of experiments/simulations; actually, such approach is one of the most utilized for fitting a second order response surface. In particular, the design of experiments illustrated in Table1 was formulated for the two design variables.

Table 1: The utilized design variables levels

\begin{tabular}{|c|c|c|c|c|c|}
\hline \multirow{2}{*}{$\begin{array}{c}\text { Design } \\
\text { variables }\end{array}$} & \multicolumn{5}{|c|}{ DOE Levels } \\
\cline { 2 - 6 } & $-\alpha$ & -1 & 0 & 1 & $+\alpha$ \\
\hline$\mu$ & 0.092 & 0.1 & 0.12 & 0.14 & 0.148 \\
\hline BHF $[\mathrm{kN}]$ & 64 & 80 & 120 & 160 & 176 \\
\hline
\end{tabular}

The designed simulations were carried out at the varying of the design variables, thus, the maximum thinning ( $t \%)$ and the springback amount $(d)$ were obtained. Figure 2 
shows springback numerical distribution and Figure 3 shows thinning distribution for one of the simulations of the DOE, in particular the one with $\mu=0.12$ and $\mathrm{BHF}=120[\mathrm{kN}]$.

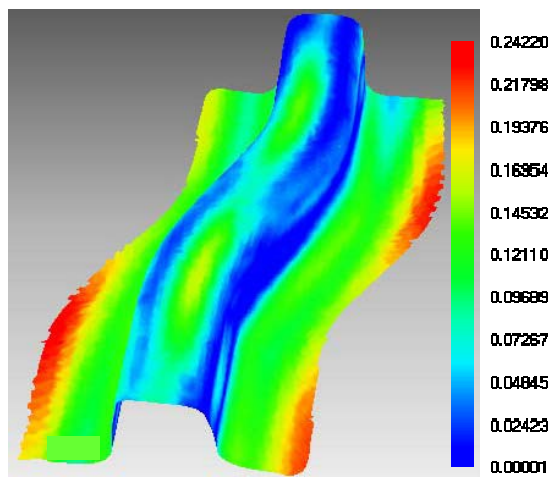

Figure 2: Springback distribution (d [mm])

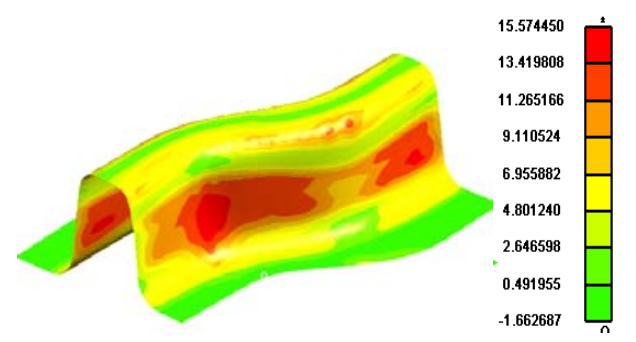

Figure 3: Thinning distribution (t[\%])

\section{DISCUSSION OF THE RESULTS AND CONCLUSIONS}

Once the designed numerical simulations were developed, Step 4 and 5 of the procedure were developed and two response surfaces were determined for the two objective functions (see Figure 4 and 5 showing respectively thinning response surface and springback one; all the values are normalized).

The best performing response functions were obtained by an "heuristic" regression procedure (developed within Minitab Environment) by subsequent exclusions of factors which are statistically less significant [13]. Such procedure led to a third order polynomial function for thinning and to a second order one for springback both providing very satisfying correlation index. The obtained equations were tested measuring the prediction errors derived from the comparison between the predicted values of $t \%$ and $d$ and the actual numerical values; such tests demonstrated the good prediction capability of the two surfaces. Once the effectiveness of the response surfaces was tested, the determination of Pareto optimal solutions was performed. The technique utilized to determine Pareto solutions was the $\varepsilon$-constraint procedure. In particular, the thinning function was chosen as primary function to be optimized in the development of the $\varepsilon$-constraint method. The resulting Pareto curve was determined and it is reported in Figure
6 in which the Pareto frontier is illustrated by plotting the curve $t \%$ vs. $d$. The obtained frontier is an effective design tool since it provides a set of Pareto optimal solutions: by fixing a desired level of thinning, for instance, it is possible to foresee which minimum possible level of springback has to be expected. Furthermore, some points belonging to the Pareto frontier were numerically reproduced (for instance, see points from 1 to 3 evidenced in Figure 6). The results corresponding to the three Pareto points are illustrated in Figure 7 as springback is concerned and in Figure 8 as thinning is regarded.

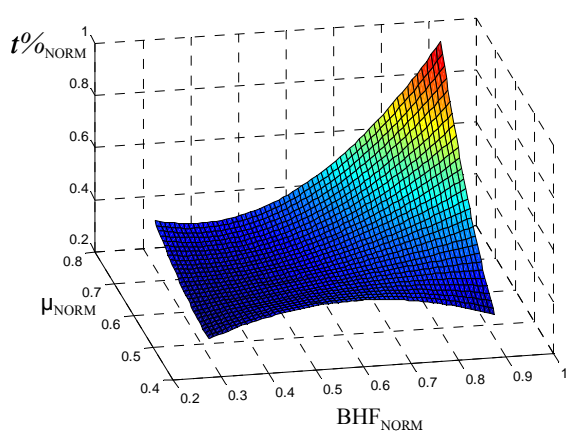

Figure 4: Response surface for thinning

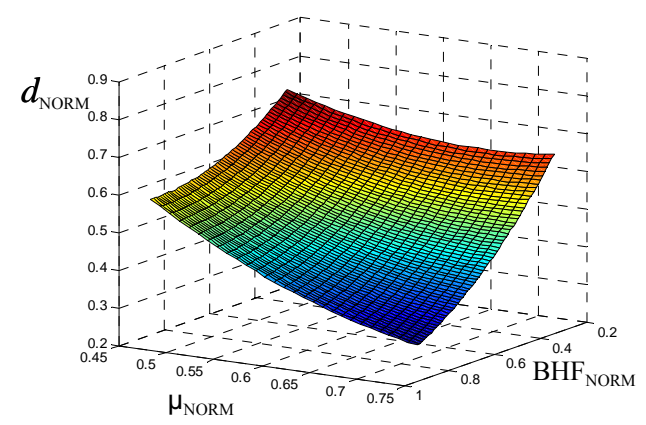

Figure 5: Response surface for springback

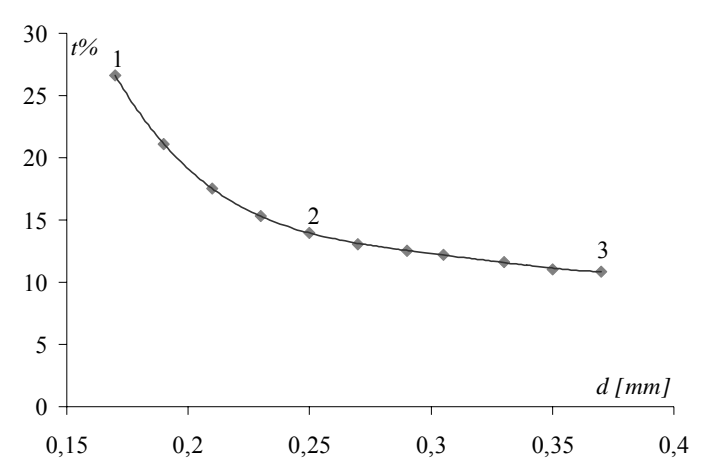

Figure 6: Pareto frontier

Moreover, for each point belonging to the Pareto frontier, it is possible to know which combination of the design variables (BHF and friction coefficient values) corresponds to the given thinning and springback levels. Thus, it is possible to consider the obtained curve as a design tool in order to define design variables with a 
strong awareness of the final results in terms of goals which can be reached.

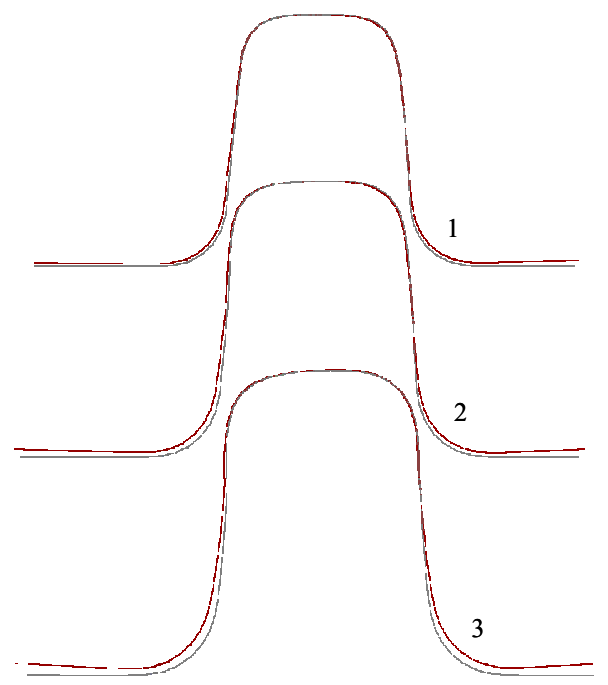

Figure 7: Comparison between desired shape and obtained one (springback effect) for points 1-2-3 of the Pareto frontier

1
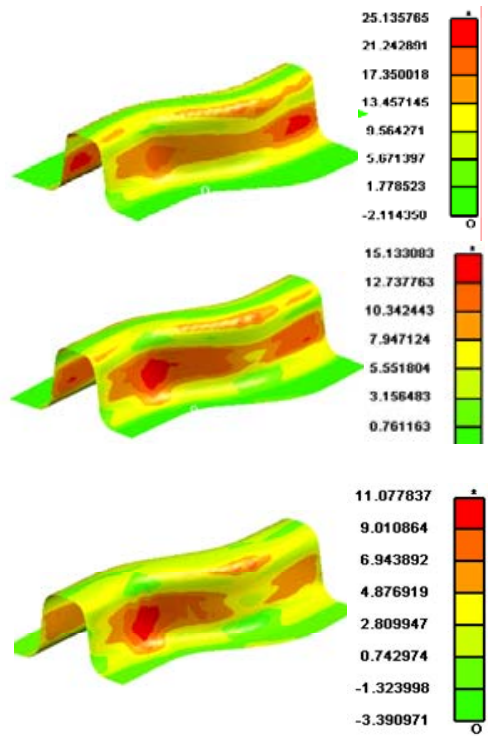

Figure 8: Thinning for points 1-2-3 of the Pareto frontier

Table 3 shows the design variables values for the chosen points. The obtained values are very coherent with the corresponding thinning and springback occurrence.

Such consideration allows assessing the effectiveness of the developed design tool. Actually, the obtained results prove the efficacy of the proposed approach.

Table 2: Design variables for points 1-2-3 of the Pareto frontier

\begin{tabular}{|c|c|c|c|}
\hline \multirow{2}{*}{$\begin{array}{c}\text { Design } \\
\text { variables }\end{array}$} & \multicolumn{3}{|c|}{ Pareto points } \\
\cline { 2 - 4 } & 1 & 2 & 3 \\
\hline$\mu$ & 0.138 & 0.125 & 0.09 \\
\hline BHF $[\mathrm{kN}]$ & 160 & 104 & 64 \\
\hline
\end{tabular}

\section{REFERENCES}

[1] Banu M., Takamura M., Hama T., Naidim O., Teodosiu C., Makinouchi A.: Simulation of springback and wrinkling in stamping of dual phase steel rail-shaped part. Journal of Material Processing Technology, 173: 178-184, 2006.

[2] Koc M.,Chen P.: Simulation of springback variation in forming of advanced high strength steels. Journal of Materials Processing Technology 190: 189-198, 2007.

[3] Asgari M., Pereira B.F., Rolfe M., Dingle P.D, Hodgson S.A.: Statistical analysis of finite element modeling in sheet metal forming and springback analysis. Journal of Material Processing Technology, 203: 129-136, 2008.

[4] Xu W.L., Ma C.H., Li C.H., Feng W.J.: Sensitive factors in springback simulation for sheet metal forming. Journal of Material Processing Technology, 151: 217 -222, 2004.

[5] Fratini L., Ingarao G., Micari F.: On the springback prediction in $3 \mathrm{~d}$ sheet metal forming processes. Steel Research International, 2008.

[6] A. Faust, K. Roll. Numerical springback evaluation for modern high strength steels using advanced material models. Proceeding of VII Numisheet Conference, pages 503-507, 2008.

[7] A. Mangas, A. Arroyo, I. Fernandes, B. Gonzalez. Improvement of springback FEM simulation by means of an optimization procedure based on an experimental trial. Proceedings of IDDRG Conference, pages 153-160, 2006.

[8] Messac A., Mullur A.A.: A computationally efficient metamodeling approach for expensive multiobjective optimization. Optimisation Engineering, 9: 37-67, 2008.

[9] Marler T. R., Chang-Hwan K., Arora J. S.: System identification of simplified crash models using multi-objective optimization. Comput. Methods Appl. Mech. Engrg, 195: 4383-4395, 2006.

[10] Firat M.: U-channel forming analysis with an emphasis on springback deformation. Materials and Design, 28:147-154, 2007.

[11] Papeleux L., Ponthot J.P.: Finite element simulation of springback in sheet metal forming. Journal of Materials Processing Technology, 125-126: 785791, 2002.

[12] Barlat F., Lian F. J.: Plastic behaviour and stretchability of sheet metal Part1. A yield function for orthotropic sheets under plane stress conditions. International Journal of Plasticity, 5: 51-66, 1989.

[13] Myers R.H., Montgomery D.C.: Response Surface Methodology Process and Product Optimization using Designed Experiments, John Wiley and Sons, Inc., New York, USA, 2nd ed. 2002. 